See Article page 1346.

\section{Commentary: Flowers against nonflowers}

\author{
Shriprasad R. Deshpande, MD, ${ }^{\mathrm{a}, \mathrm{b}}$ Yasin Essa, MD, ${ }^{\mathrm{a}}$ \\ and Can Yerebakan, $\mathrm{MD}^{\mathrm{a}} \mathrm{b}$
}

The aim of performing a separate Glenn procedure as a preFontan stage is to maintain oxygen saturation, allowing growth of the pulmonary artery and thereby enabling a potentially successful Fontan completion. ${ }^{1}$ This has overcome some of the shortcomings of the previous era, when Fontan cavopulmonary anastomoses were performed in a single stage and often failed in younger patients. ${ }^{2,3}$ Performing a Glenn anastomosis at around age 4 to 6 months followed by Fontan at age 2 to 3 years seems to have become the standard of care; however, the morbidity and mortality associated with Fontan failure remain persistent and high. ${ }^{4}$

In patients with an appropriate anatomic substrate, surgeons have the option of terminating antegrade pulmonary blood flow (PBF) or leaving it partially patent at the time of the Glenn operation. Because a bidirectional Glenn procedure without an atrial septectomy can be performed on a beating heart, there is no need for cardioplegic arrest if no intervention is planned on the pulmonary artery. The major incentive for leaving antegrade flow comes from the potential for pulmonary artery growth. A restrictive but pulsatile antegrade flow may promote pulmonary artery growth, improve flow through the pulmonary vascular bed, and potentially lower vascular resistance. ${ }^{5,6}$ Although additional antegrade flow allows for augmentation of pulmonary blood during exercise, an inferior vena caval contribution may help possibly reduce arteriovenous malformations within the lungs via hepatic factor. There also may be a reduced tendency to form venovenous collaterals. ${ }^{6,7}$

From the Departments of a Cardiology and ${ }^{\mathrm{b} C a r d i o v a s c u l a r}$ Surgery, Children's National Heart Institute, Children's National Hospital, The George Washington University School of Medicine and Health Sciences, Washington, DC.

Disclosures: The authors reported no conflicts of interest.

The Journal policy requires editors and reviewers to disclose conflicts of interest and to decline handling or reviewing manuscripts for which they may have a conflict of interest. The editors and reviewers of this article have no conflicts of interest.

Received for publication March 26, 2021; revisions received March 26, 2021; accepted for publication March 26, 2021; available ahead of print April 1, 2021.

Address for reprints: Shriprasad R. Deshpande, MD, Department of Cardiology, Children's National Heart Institute, Children's National Hospital, The George Washington University School of Medicine and Health Sciences, 111, Michigan Ave NW, Washington, DC 20010 (E-mail: sdeshpan@childrensnational.org).

J Thorac Cardiovasc Surg 2021;162:1356-7

$0022-5223 / \$ 36.00$

Copyright (C) 2021 by The American Association for Thoracic Surgery

https://doi.org/10.1016/j.jtcvs.2021.03.089
Check for updates

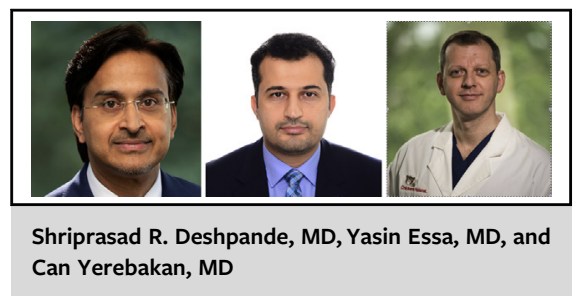

CENTRAL MESSAGE

A systematic approach is needed

to determine the anatomic and

physiologic factors in patients

with a single ventricle who will

benefit from antegrade pulmo-

nary blood flow following supe-

rior cavopulmonary anastomosis.

Allowing antegrade pulsatile flow can increase the Glenn pressures and thus the pressure in the superior vena cava with increased pleural effusions postoperatively. ${ }^{8}$ A longterm consequence of the additional source of PBF may be unnecessary volume load on the single ventricle carrying forward the inefficiency usually associated with stage I. It is important to note that study findings have not been reproducible and in fact have been contradictory in terms of both postoperative and long-term findings. An example of the this is the study by Chen and colleagues.

In this light, the study by Baek and colleagues ${ }^{10}$ published in this issue of the Journal provides a select cohort of patients with antegrade blood flow pre-Glenn and provides a follow-up of this cohort following the Glenn and Fontan stages. At the discretion of the surgeon, the patients underwent a Glenn procedure with or without persistent antegrade PBF. There are several important findings. The incidence of prolonged chest tube drainage (as a binary outcome) was similar in the 2 groups. However, if readmission for pleural effusion is considered, then those without antegrade PBF performed better. Operative mortality did not differ between the 2 groups, and there was no difference in death, dysfunction, or valve regurgitation in the interstage period. In patients with available data, there was better pulmonary artery growth and higher saturations with antegrade flow. The pulmonary vascular resistance was lower in those with antegrade flow, and there was no increase in end-diastolic pressure, possibly indicating an undesirable consequence of volume loading or reflecting ventricular dysfunction. In general, the immediate post-Fontan 
outcomes were similar, except for a longer stay in those without antegrade blood flow.

A similar number of deaths occurred in the 2 groups postFontan. However, in an inverse probability of treatmentweighted analysis, the authors estimated that at 15 years, those with antegrade flow were 2.37 more likely to die or undergo transplantation compared to those without antegrade flow. Of note, the actual mean duration of follow-up for the groups was approximately 8 years.

It is important to recognize that the option of antegrade PBF is available only in a limited group of patients among those undergoing Glenn to Fontan palliation. Patient selection may be very important. Those with ventricular dilatation or ventricular dysfunction before Glenn may certainly benefit from complete termination of antegrade PBF. Cases with significant atrioventricular valve regurgitation may benefit from valvuloplasty at the time of the Glenn. Better growth of the pulmonary artery and the vascular bed in general may provide a better setup for Fontan procedure. It is also possible that the additional PBF may allow for a longer period before Fontan completion is needed from a saturation level standpoint. Would this allow the push of Fontan to age 3 to 4 years rather than 2 to 3 years? Does that short delay provide further growth allowance for the pulmonary arteries? A critical point is that in these reports, it is challenging to determine the proper amount of antegrade PBF, which may certainly impact the outcomes. Antegrade PBF is often treated as a yes/no classification. Measurement of central venous pressure in the operating room may be a poor reflection of the quantity of the antegrade PBF. It is possible that the actual amount of antegrade PBF required to reap the benefit may be quite small. The volume load on the single ventricle at stage I palliation is roughly $250 \%$ to $300 \%$ of the load for the corresponding body surface area. At the Glenn stage, this is generally reduced to approximately $90 \%$ of the load for corresponding body surface area and at Fontan stage to $50 \%$ to $80 \%$. ${ }^{11}$ Thus, an effectively restrictive band on the antegrade flow may provide a small degree of pulsatility without deleterious volume loading. A $10 \%$ to $20 \%$ additional flow compared with Glenn only via the antegrade flow may be ideal for preventing arteriovenous malformations as well as hypoxia-driven collaterals. It is important to then systematically quantify effective PBF using catheterization and newer modalities, such as 4dimensional magnetic resonance imaging. We also need to acknowledge that the theoretical volume loading with antegrade PBF has not been a consistent finding. ${ }^{12}$ Finally, interstage management of these patients from the medical standpoint has not been adequately studied. Long-term use of phosphodiesterase inhibitors, such as sildenafil, after Glenn may be beneficial and requires systematic analysis.

In a surgical community that is striving toward improving outcomes for single ventricle patients rather than being dogmatic about such issues as antegrade PBF, a more pragmatic approach that emphasizes patient selection and more thoughtful, systematic strategy may be beneficial. We thank the authors for their excellent contribution.

\section{References}

1. Trusler GA, Williams WG, Cohen AJ, Rabinovitch M, Moes CA, Smallhorn JF, et al. William Glenn lecture. The cavopulmonary shunt. Evolution of a concept. Circulation. 1990;82(5 Suppl):Iv131-8.

2. Hopkins RA, Armstrong BE, Serwer GA, Peterson RJ, Oldham HN Jr. Physiological rationale for a bidirectional cavopulmonary shunt: a versatile complement to the Fontan principle. J Thorac Cardiovasc Surg. 1985;90:391-8.

3. Norwood WI, Jacobs ML. Fontan's procedure in two stages. Am J Surg. 1993; 166:548-51.

4. Kutty S, Jacobs ML, Thompson WR, Danford DA. Fontan circulation of the next generation: why it's necessary, what it might look like. J Am Heart Assoc. 2020;9 e013691.

5. Caspi J, Pettitt TW, Ferguson TB Jr, Stopa AR, Sandhu SK. Effects of controlled antegrade pulmonary blood flow on cardiac function after bidirectional cavopulmonary anastomosis. Ann Thorac Surg. 2003;76:1917-21; discussion 1921-2.

6. Ferns SJ, El Zein C, Subramanian S, Husayni T, Ilbawi MN. Post-Fontan pulmonary artery growth in patients with a bidirectional cavopulmonary shunt with additional antegrade pulsatile blood flow. Asian Cardiovasc Thorac Ann December 25, 2020 [Epub ahead of print].

7. Gray RG, Altmann K, Mosca RS, Prakash A, Williams IA, Quaegebeur JM, et al Persistent antegrade pulmonary blood flow post-Glenn does not alter early postFontan outcomes in single-ventricle patients. Ann Thorac Surg. 2007;84:888-93; discussion 893.

8. Calvaruso DF, Rubino A, Ocello S, Salviato N, Guardì D, Petruccelli DF, et al. Bidirectional Glenn and antegrade pulmonary blood flow: temporary or definitive palliation? Ann Thorac Surg. 2008;85:1389-95; discussion 1395-6.

9. Chen Q, Tulloh R, Caputo M, Stoica S, Kia M, Parry AJ. Does the persistence of pulsatile antegrade pulmonary blood flow following bidirectional Glenn procedure affect long term outcome? Eur J Cardiothorac Surg. 2015;47:154-8; discussion 158 .

10. Baek JS, Park CS, Choi ES, Yun T-J, Kwon BS, Yu JJ, et al. The impact of additional antegrade pulmonary blood flow at bidirectional Glenn shunt on long-term outcomes. J Thorac Cardiovasc Surg. 2021;162:1346-55.e4.

11. Gewillig M, Brown SC. The Fontan circulation after 45 years: update in physiology. Heart. 2016;102:1081-6.

12. Berdat PA, Belli E, Lacour-Gayet F, Planché C, Serraf A. Additional pulmonary blood flow has no adverse effect on outcome after bidirectional cavopulmonary anastomosis. Ann Thorac Surg. 2005;79:29-36; discussion 36-7. 